\title{
Mechanical Properties of Hybrid Cementitous Composites
}

\section{I.O. Oladele*, A.D. Akinwekomi and U. Donatus}

\begin{abstract}
Department of Metallurgical and Materials Engineering, Federal University of Technology, Akure, Ondo State, Nigeria.
\end{abstract}

*Corresponding author: wolesuccess2000@yahoo.com

\begin{abstract}
Pulverised stem fibres of the natural sponge plant, SP, (Acanthus montanus) and stranded coconut fibre, CF, (Cocos nucifera) from the coir tree were used as reinforcements for thin cement sheets in this research work. The mixture of cement and pulverised waste paper, which formed the matrix, was maintained constant while the fibre mass concentration of both fibres were varied. The slurry formed by adding water to the mixture of the matrix materials and the reinforcement fibres, was poured into rectangular mould and consequently pressed to eject excess water. De-moulded samples were allowed to cure in the laboratory for twentyeight days before flexural and compressive tests were carried out. The analysis of the experimental results established that sample coded as S4, with 30\% CF and 70\% SP, showed the most promising result. This implied that particulate reinforcement in cement matrix composite contributed to higher and improved flexural load bearing capacity and ductility when utilised in a higher proportion than long fibres.
\end{abstract}

Keywords: Mechanical properties, hybrid, natural sponge, coconut fibre, cement matrix. 


\section{INTRODUCTION}

The use of fibres as reinforcement is as old as human civilization. Traces of natural fibres such as flax, cotton, silk, wool and plant fibres have been located in ancient civilizations all over the globe. For example, the recorded usage of flax can be dated back to 5000 BC; it is considered the oldest natural textile fibre $[1,2]$. More recently, the use of natural fibres in construction has been limited to thin elements for roofing, cladding, and internal and external partitioning walls; these have been produced in an effort to develop low cost materials and as a substitute for asbestos, especially in the developing economies.

Today, a deficit of habitations is a major problem in both developed societies and developing countries. Little attention is given to the problem; while millions of people live in sub-human conditions, the majority of researchers direct their projects towards the development of advanced materials and sophisticated analysis of structural systems [3].

The development of low cost materials with high durability and enhanced mechanical properties becomes a real challenge to the engineers of the 21st century. Environmental issues such as the greenhouse effect have also become major concerns. The lee way may, perhaps, be viewed in bio-degradable composite systems with low cement content. These composites can find applications in various fields such as permanent formworks, rowingboats, facades, tanks, domestic pipes, corrugated and flat roofing elements, insulating panels, strengthening of existing structures and structural building members.

The geometrical increase in the world population signifies that more reinforced concrete structures will be built with an accompanying deterioration problems coupled with increase in the demand for non-renewable resources [4].

Natural fibres are a renewable resource and are available almost all over the world [5]. Therefore to promote the use of concrete reinforced with natural fibres could be a viable way to improve concrete durability and sustainable construction which will alleviate the problems of housing and environmental degradation resulting from the use of non-renewable resources.

Therefore, the aim of this paper is to make use of the combination of coconut fibre of a 
specified length and particulate natural sponge fibre for the production of ceiling board for the building industry.

\section{MATERIALS AND METHODS}

The materials used for this research work were all sourced and obtained locally. These included fibres from the stem of the natural sponge plant, SP, (Acanthus montanus), coconut fibre, CF, (Cocos nucifera) from the coir tree, pulverised waste paper from old newspaper pages, wooden moulds, polythene sheets and Portland cement. The CF were cut down to 40mm length to avoid balling problem during mixing and to facilitate homogeneous mixing of the composite [6] while the SP fibres were pulverised.

The variable in this research work was fibre mass concentration. The mixture of cement and waste paper in the ratio 70:30 by weight was maintained constant. The fibre mass fractions, $\mathrm{M}_{f}$ aimed at were $\mathrm{M}_{f}=0,2,4,6,8$ and $10 \%$. This fibre mass fraction was defined as the ratio of fibres to the dry constituents of the matrix (cement and waste paper) by weight [7]. Table 1 below gives the matrix and fibre mass compositions utilized for this research work.

Table 1. Matrix and Fibre Mass Compositions

\begin{tabular}{|c|c|c|c|c|c|c|c|c|c|c|}
\hline & \multicolumn{10}{|c|}{ Composition } \\
\hline Fibre & S1 & S2 & S3 & S4 & S5 & S6 & S7 & S8 & S9 & S10 \\
\hline CF & $0 \%$ & $10 \%$ & $20 \%$ & $30 \%$ & $40 \%$ & $50 \%$ & $60 \%$ & $70 \%$ & $80 \%$ & $90 \%$ \\
\hline SP & $0 \%$ & $90 \%$ & $80 \%$ & $70 \%$ & $60 \%$ & $50 \%$ & $40 \%$ & $30 \%$ & $20 \%$ & $10 \%$ \\
\hline
\end{tabular}

Weighed masses of pulverised paper, cement and fibres were homogeneously mixed together. Water was then added until suitable slurry was formed. The slurry was poured into the rectangular moulds measuring 150mm X 50mm X 30mm and labelled with the corresponding mass fraction. A-5 ton hydraulic jack was used in compressing the composites for approximately one hour until excess water was dispelled before they were de-moulded. The composites produced were allowed to cure in the laboratory air for twenty-eight days before mechanical tests were carried out. Three samples were tested for each formula and a mean of the results was recorded. 


\subsection{Flexural and Compressive Tests}

Flexural test based on the three-point loading principle was carried out on the Tensometric Testing Machine. The flexural load (force at peak) and deflection at yield were automatically generated by the machine. The compressive test was also done on the same machine.

\section{RESULTS AND DISCUSSION}

\subsection{Flexural Load}

The flexural load (force) is the maximum load the composite can bear before fracture during flexure/ bend test [6]. Figure 1 depicts the results graphically.

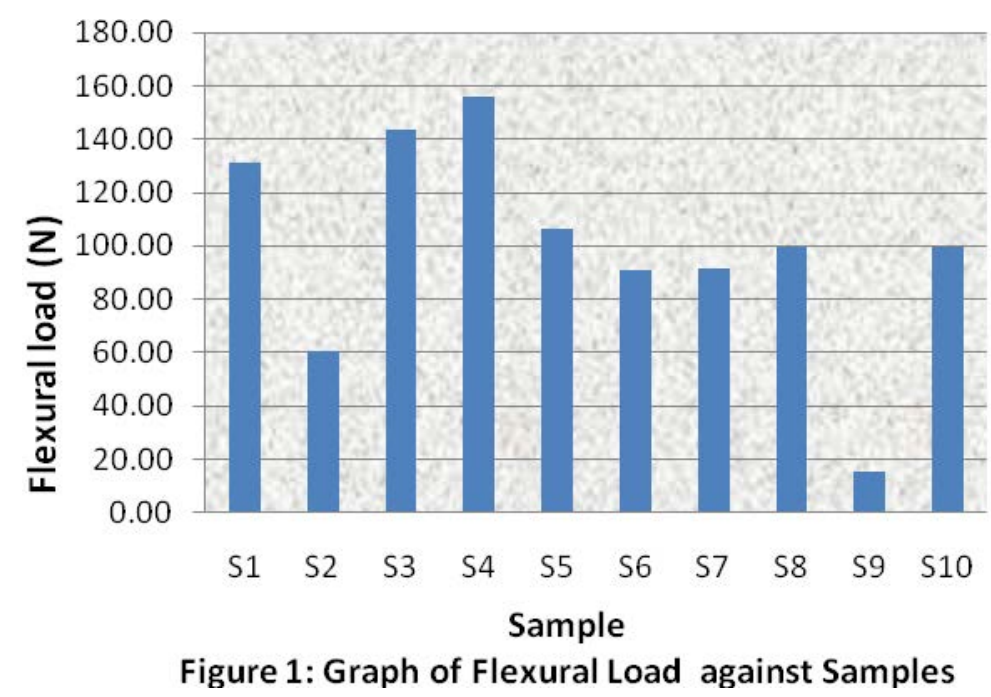

Samples S3 and S4 exhibited the higher and highest resistances to applied load respectively, with S3 having $143.75 \mathrm{~N}$ while S4 had $156.10 \mathrm{~N}$. S1 closely followed with a value of 130.95 N. However, S9 had the lowest value of $115.35 \mathrm{~N}$. The trend observed was that as the CF fraction increased in the matrix, the flexural strength also increased from S2-3, reaching a peak for S4, before declining for S9. The implication of this is that the fibres included in the matrix actually contributed to strengthening and delayed matrix cracking according to Brandt, 2008. SP, in the particulate form seemed to show better strengthening when it has a higher volume fraction in the matrix than CF. S10, however, did not follow the observed trend. It showed quite a high resistance to fracture with a value of $99.70 \mathrm{~N}$. The relatively high flexural load could have been due to CF, being present in a larger fraction than SP. 


\subsection{Flexural Deflection (Mid-span deflection)}

The flexural (mid-span) deflection is a measure of both the ductility and toughness of each of the samples [6]. The results of this test are presented in Figure 2 below:

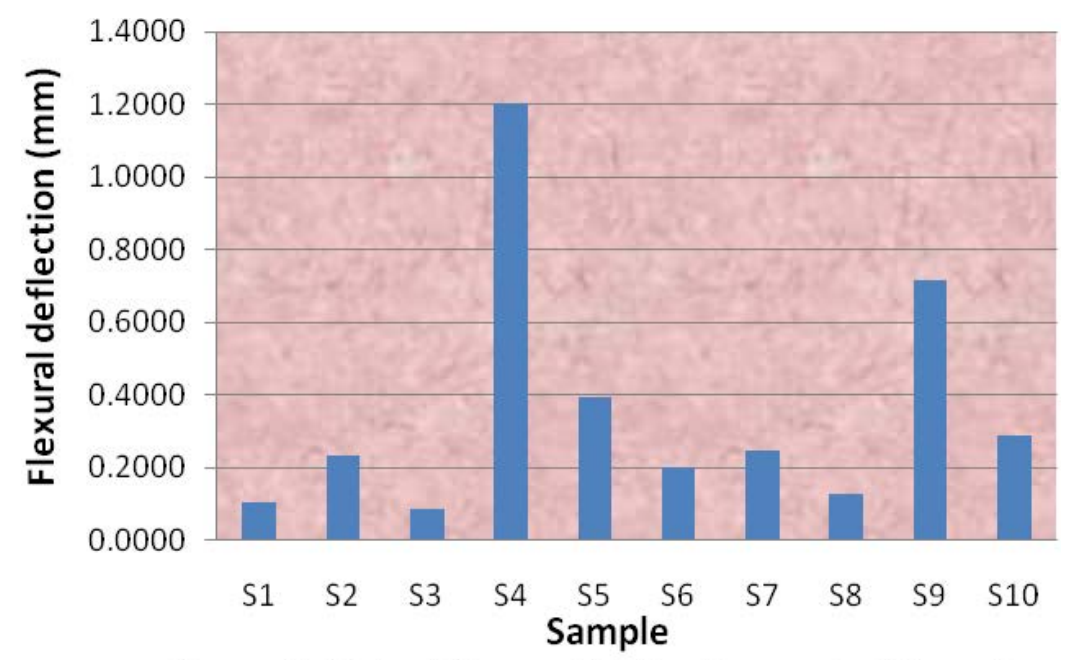

Figure 2: Plot of Flexural Deflection against Samples

S4 had the highest ductility value of $1.2 \mathrm{~mm}$ while S3 had the poorest ductility with a value of $0.0870 \mathrm{~mm}$. This was followed closely by the control sample, S1, with a recorded value of $0.1070 \mathrm{~mm}$. Excepting the S3 sample, the fibre reinforcement generally improved ductility when compared with S1, the unreinforced sample. Improvement in ductility was, however, not prominent for S3 and S8 (values of $0.0870 \mathrm{~mm}$ and $0.1300 \mathrm{~mm}$ respectively). S9 also exhibited the next higher value of ductility of $0.7155 \mathrm{~mm}$. It contained a higher fibre fraction of CF than SP. Though no general trend could be established for this property, some extreme peaks could be established, especially for S4 (higher fibre fraction of SP) and S9 (with a higher proportion of CF).

\subsection{Compressive Load}

The compressive strength reported is compressive force at peak. The results are shown in Figure 3 below:

S1 exhibited the highest resistance to compressive load, with a value of $5737.0 \mathrm{~N}$. This was followed closely by S4 and S3, with values of $5193 \mathrm{~N}$ and $4476.0 \mathrm{~N}$ respectively. The high resistance to compression depicted by S1 could be attributed to the presence of few or no air 
pores in its matrix. The incorporation of fibres into the matrix introduced some air pores. This accounted for the reduction in the compressive loads that could be sustained by the test samples. This is also true for the other reinforced samples (i.e.S2 to S10).

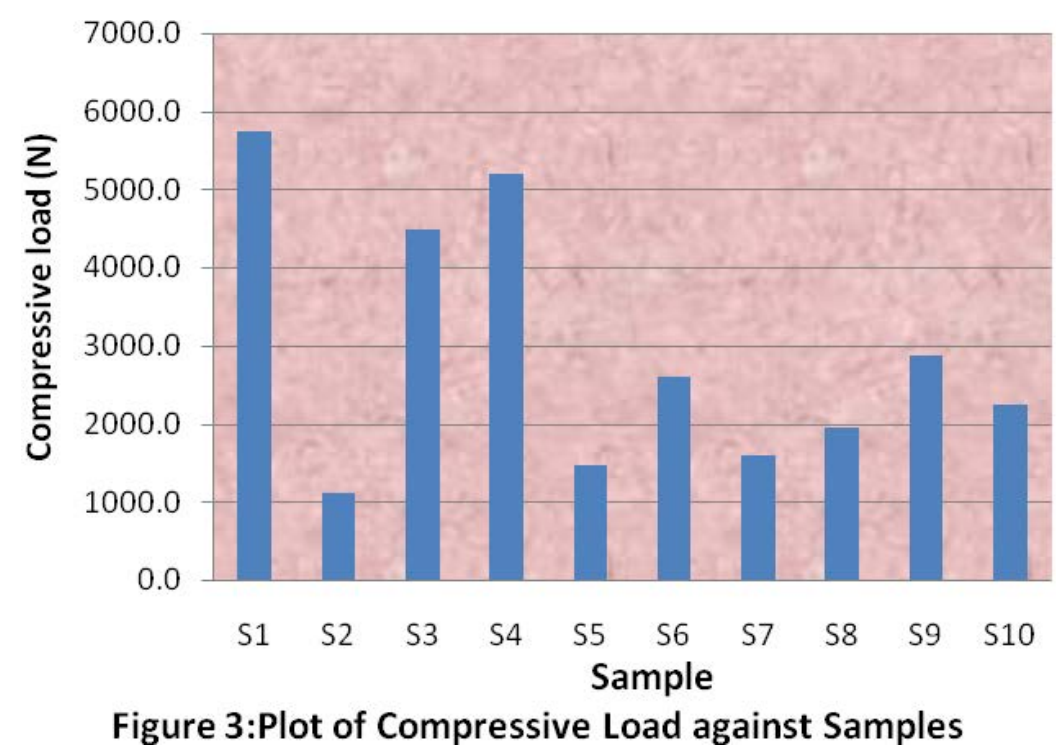

\section{CONCLUSION}

The results and analyses of the data obtained from this research work showed that randomly distributed natural vegetable fibres could be used to improve the flexural strength of flat cement composite sheets. S4, with 30\% CF and 70\% SP, showed the most promising result. This implied that particulate reinforcement in cement matrix composite contributed to higher and improved flexural load bearing capacity and ductility as measured by the mid-span deflection. Compressive load was not adversely affected by the inclusion of fibres in the S4 sample. Strength and ductility showed better improvement at the optimum fibre mass fraction of $70 \%$ SP and $30 \%$ CF.

\section{REFERENCES}

1. Silva, F. and Filho Toledo, R., 2008, "Sisal Fibre Reinforcement of Durable Thin-walled Structures- A New Perspective”, CBM-CI International Workshop, Karachi, Pakistan. 
2. Toledo, F.R.D., Ghavami, K., England, G.L., and Scrivener, K., 2003, "Development of Vegetable Fibre-Mortar Composites of Improved Durability”, Cement \& Concrete Composites, Vol. 25, pp. 185-196.

3. Toledo, F.R. D., Americano, B. B., Fairbairn, E. M. R., Rolim, J. S., and Filho, J. F., 2001, "Potential of Crushed Waste Calcined-Clay Brick as a Partial Replacement for Portland CEMENT”, In: Third CANMET/ACI International Symposium on Sustainable Development, San Francisco, pp.147 - 157.

4. Mora, E., 2007, Building and Environment, Vol. 42, pp. 1329-1334.

5. Brandt, A., 2008, Composite Structures, Vol. 86, pp. 3-9.

6. Oladele, I.O., Akinwekomi, A.D., Aribo, S., and Aladenika, A.K., 2009, “Development of Fibre Reinforced Cementitious Composite for Ceiling Application”, Journal of Minerals \& Materials Characterization \& Engineering, Vol. 8, No.8, pp 591-598.

7. Soroushian, P. and Mankunte, S., 1990, High Performance Fibre Reinforced Cement Composites, (eds. H.W. Reinhardt and A.E. Naaman), E and FN Son, London, pp. 84-99. 